\title{
Average Friction Factor for Laminar Gas Flow in Microtubes
}

\author{
Chungpyo Hong ${ }^{1,{ }^{*}}$, Yutaka Asako ${ }^{2}$, Mohammad Faghri $^{3}$, Gian Luca Morini ${ }^{4}$ \\ Department of Mechanical Engineering, Kagoshima University, Kagoshima 890-8580, Japan \\ 2 Department of Mechanical Precision Engineering, Malaysia-Japan International Institute of Technology, Universiti Teknologi Malaysia, Kuala \\ Lumpur, 54100 Kuala Lumpur, Malaysia \\ 3 Department of Mechanical, Industrial and Systems Engineering, University of Rhode Island Kingston, RI 02881, USA \\ 4 Department of Industrial Engineering, University of Bologna, Via del Lazzaretto 15/5, 40131 Bologna, Italy
}

\section{ARTICLE INFO}

\section{Article history:}

Received 22 January 2020

Received in revised form 17 March 2020

Accepted 22 March 2020

Available online 28 March 2020

Keywords:

Average friction factor; Mach number;

Gas flow; Microtube

\section{ABSTRACT}

\begin{abstract}
The average friction factor in micro tubes will help the design engineers to estimate the pressure loss in micro flow devices. The aim of the present study is to obtain numerically average Darcy and Fanning friction factors and Mach numbers between the inlet and outlet of gas flows through adiabatic microtubes. This paper presents the average Poiseuille numbers, $\left(f_{\mathrm{d}} \cdot R e\right)_{\text {ave }} \&\left(f_{\mathrm{f}} \cdot R e\right)_{\text {ave, }}$, between the inlet and outlet, those are obtained from numerical results for laminar gas flow in microtubes with diameters of 50, 100 and $150 \mu \mathrm{m}$ and aspect ratios (i.e. length/diameter) of 100, 200 and 400, respectively. Axis-symmetric compressible momentum and energy equations were solved with the Arbitrary-Lagrangian-Eulerian (ALE) method. The stagnation pressure was chosen in such a way that the outlet Mach number ranged from 0.1 to 1.0. The outlet pressure was fixed at atmospheric condition. As a result, the average Darcy and Fanning friction factors between the inlet and outlet were obtained and compared with Moody's chart. The $\left(f_{\mathrm{d}} \cdot R e\right)_{\text {ave }}$ and $\left(f_{\mathrm{f}} \cdot R e\right)$ ave were also obtained and presented as a function of average Mach number and were compared with the local $f \cdot R e$ correlations proposed in the previous study.
\end{abstract}

Copyright @ 2020 PENERBIT AKADEMIA BARU - All rights reserved

\section{Introduction}

Development of the MEMS technology has increased the need for understanding of fluid flow in micro flow devices such as micro-valves, micro-pumps, micro-reactor and for many other micro fluid systems [1]. A microchannel passage is the basic and important element in the design of micro flow devices and for this reason during the last decade a series of investigations have been conducted with the aim of clarifying the role of scale effects in microchannels [2]. From the early work by $\mathrm{Wu}$ and Little [3], numerous experimental and numerical investigations on microchannel gas flow have been undertaken as shown in the comprehensive review by Kawashima and Asako [4].

\footnotetext{
* Corresponding author.

E-mail address: hong@mech.kagoshima-u.ac.jp (Chungpyo Hong)
} 
The pressure loss determined using an appropriate friction factor between two points is important design information. There are two definitions of friction factors based on pressure drop, namely, Darcy and Fanning friction factors. Both friction factors for gases with large variations in physical properties were obtained solely under the assumption of isothermal flow by most investigators [3, 5-9]. This is because of the measurement limitations in gas temperature flowing through micro-channels. Fortunately, for gas flow through a micro-channel with thermally insulated wall (adiabatic wall), the estimation of gas static temperature at the micro-channel outlet can be obtained using a quadratic equation proposed by Kawashima and Asako [10]. A new data reduction methodology for the average Fanning friction factor calculation between the inlet and outlet, considering the effect of the decrease in gas temperature, has been developed by Hong et al., [11]. Rehman et al., [12] and Hong et al., [13] experimentally and numerically investigated the average friction factor for adiabatic microchannels in compressible gas flows including choked flows.

Attention will now be focused on $f \cdot \operatorname{Re}$, the product of a friction factor and the Reynolds number for microchannel gas flows. Asako et al., [14, 15] and Hong et al., [16-19] conducted numerical investigations on gas flow characteristics in microchannels for both no-slip and slip boundary conditions. They proposed local $f$. Re correlations as a function of Mach number and Knudsen number corresponding to compressibility and rarefaction effects for quasi-fully developed laminar flow. Their local $f$. Re correlations were in excellent agreement with the experimental data of Hong et al., $[9,20]$. They also reported pressure variations and mass flow rate for microchannel gas flow using the $f \cdot$ Re correlations $[21,22]$. However, there seems to be no investigation on the average $f \cdot \operatorname{Re}$, the product of average friction factor and Reynolds number, for laminar gas flows in microtubes. This motivated the present study in obtaining numerically the average Darcy and Fanning friction factor and Mach number between the inlet and outlet of gas flows through microtubes.

\section{Formulation}

\subsection{Description of The Problem}

The schematic diagram of the calculation domain in a microtube for numerical analysis is shown in Figure 1. The numerical methodology to solve the governing equations is based on the ArbitraryLagrangian-Eulerian (ALE) method. The detailed description of the numerical computation was well documented in the previous work [14] and will not be repeated here. Only a brief description is reported here. The flow is assumed to be steady, axisymmetric, and laminar and the fluid is assumed to obey ideal gas law. Compressible gas in a reservoir at the stagnation pressure, $p_{\mathrm{stg}}$, and stagnation temperature, $T_{\text {stg, }}$ passes through an adiabatic microtube and is discharged to atmosphere $\left(p_{\text {out }}=10^{5} \mathrm{~Pa}\right)$ by varying the stagnation pressure. The physical properties assumed to be constant. Inlet values of the velocity, density and temperature are obtained under an isentropic process between the inlet and the stagnation area. It is also assumed that the velocity, pressure, temperature and density profiles at the inlet are uniform and the thermal boundary condition on the wall is adiabatic.

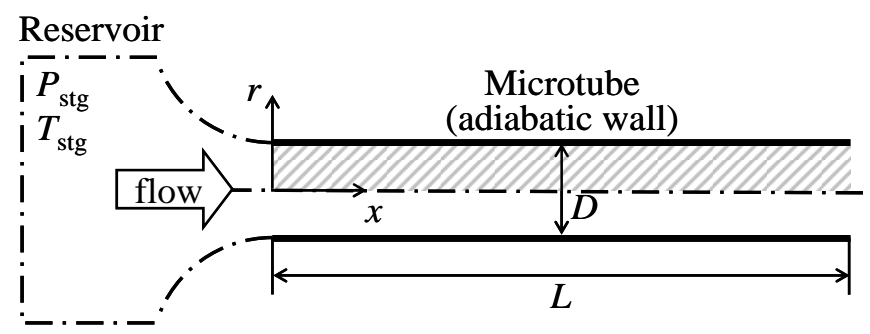

Fig. 1. Schematic diagram of the problem 


\subsection{Dimensionless Valuables}

The Reynolds number and Mach number are defined as

$\operatorname{Re}=\frac{\bar{u} D}{\mu / \bar{\rho}}$

$M a=\frac{\bar{u}}{\sqrt{\gamma(\gamma-1) \bar{t}}}=\frac{\bar{u}}{\sqrt{\gamma R T}}$

where $D$ is a tube diameter. $\bar{u}, \bar{\rho}$ and $\bar{\imath}$ are the average velocity, density and specific internal energy at the cross-section as follows

$\bar{u}=\frac{1}{A} \int u \mathrm{dA}, \bar{\rho}=\int \rho u \mathrm{~d} \mathrm{~A} / \int u \mathrm{dA}$,

$\bar{p}=\frac{1}{A} \int p \mathrm{dA}, \bar{\imath}=\frac{1}{\gamma-1} \frac{\bar{p}}{\bar{\rho}}, \bar{T}=\frac{\bar{p}}{R \bar{\rho}}$

The average Mach number between the inlet and the outlet can be defined as

$M a_{\text {ave }}=\frac{\bar{u}_{\text {ave }}}{\sqrt{y R T_{\text {ave }}}}$

where the average velocity, $\bar{u}_{\text {ave }}$ and the average temperature, $\bar{T}_{\text {ave }}$ can be obtained by integrating between the inlet $\left(x_{1}\right)$ and outlet $\left(x_{2}\right)$ as

$\bar{u}_{\text {ave }}=\frac{1}{x_{\mathrm{z}}-x_{1}} \int_{x 1}^{x 2} \bar{u} d x, \bar{T}_{\mathrm{ave}}=\frac{1}{x_{\mathrm{z}}-x_{1}} \int_{x \mathbf{1}}^{x 2} \bar{T} d x$

In the previous study [11], a new data reduction methodology for the calculation of the average Fanning friction factor between the inlet and outlet through adiabatic microtubes has been developed. The developed average friction factor was employed in the present study. The average Fanning and Darcy friction factors between the inlet $\left(x_{1}\right)$ and outlet $\left(x_{2}\right)$ are

$$
\begin{aligned}
& f_{\text {fave }}=\frac{1}{x_{2}-x_{1}} \int_{x_{1}}^{x_{2}} f_{f} d x=\frac{D}{x_{2}-x_{1}}\left\{\int_{x_{1}}^{x_{2}}\left(\frac{2}{\bar{p}} d \bar{p}\right)-\int_{x_{1}}^{x_{2}}\left(\frac{2 \bar{p}}{\bar{\rho}^{2} \bar{u}^{2} R \bar{T}} d \bar{p}\right)-\int_{x_{1}}^{x_{2}}\left(\frac{2}{\bar{T}} d \bar{T}\right)\right\}
\end{aligned}
$$

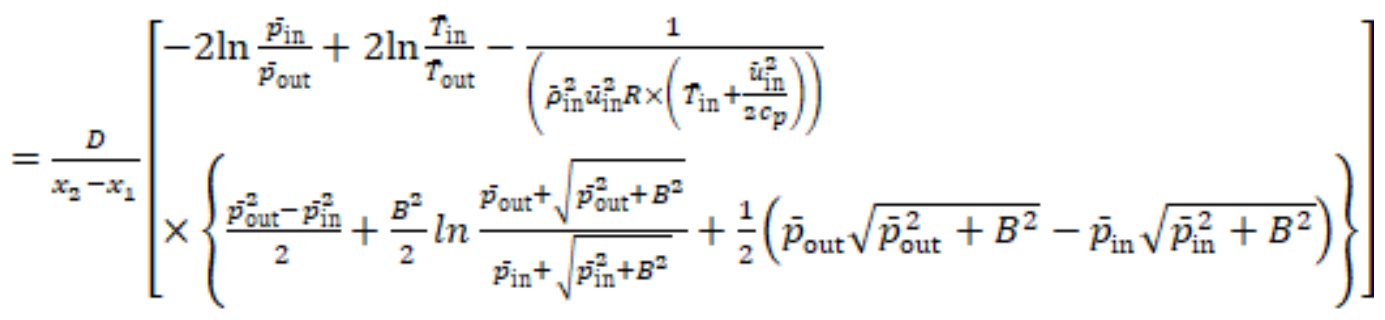

$$
\begin{aligned}
& f_{\text {d,ave }}=\frac{1}{x_{2}-x_{1}} \int_{x_{1}}^{x_{2}} f_{d} d x=\frac{D}{x_{2}-x_{1}}\left\{-\int_{x_{1}}^{x_{2}}\left(\frac{2 \bar{p}}{\bar{\rho}^{2} \bar{u}^{2} R \bar{T}} d \bar{p}\right)\right\}
\end{aligned}
$$




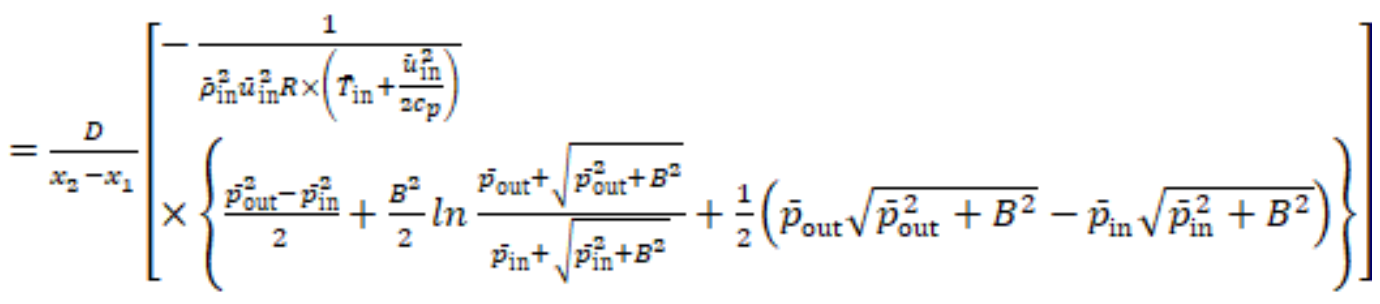

where

$$
B^{2}=4 \times \alpha \frac{\bar{\rho}_{\text {in }}^{2} \bar{u}_{i n}^{2} R^{2}}{2 \varepsilon_{p}} \times\left(\bar{T}_{\text {in }}+\frac{\bar{u}_{\text {in }}^{2}}{2 \varepsilon_{p}}\right)
$$

\section{Result and Discussion}

Numerical computations were conducted for microtubes with diameters of $D=50,100$ and 150 $\mu \mathrm{m}$ and aspect ratios of 100, 200 and 400, respectively. The tube diameter and its length, the stagnation pressure and the corresponding Reynolds number and Mach number are listed in Table

\begin{tabular}{|c|c|c|c|c|c|}
\hline$D(\mu \mathrm{m})$ & $\mathrm{L}(\mathrm{mm})$ & $p_{\mathrm{stg}}(\mathrm{kPa})$ & $\operatorname{Re}$ & $M a_{\text {in }}$ & $M a_{\text {out }}$ \\
\hline \multirow[t]{3}{*}{50} & 5 & $150-500$ & $159-1514$ & $0.096-0.287$ & $0.141-1.105$ \\
\hline & 10 & $150-600$ & 84 - 1454 & $0.051-0.225$ & $0.075-1.072$ \\
\hline & 15 & $200-700$ & $101-1245$ & $0.046-0.163$ & $0.090-0.95$ \\
\hline \multirow{3}{*}{100} & 10 & $150-375$ & $537-2595$ & $0.164-0.333$ & $0.236-0.981$ \\
\hline & 20 & $150-450$ & $316-2609$ & $0.096-0.273$ & $0.140-0.986$ \\
\hline & 40 & $150-500$ & 168 - 2195 & $0.051-0.203$ & $0.075-0.859$ \\
\hline \multirow[t]{3}{*}{150} & 15 & $150-250$ & $1019-2550$ & $0.21-0.327$ & $0.297-0.693$ \\
\hline & 30 & $150-400$ & $657-2578$ & $0.133-0.27$ & $0.194-0.7$ \\
\hline & 60 & $150-400$ & $368-2342$ & $0.074--0.206$ & $0.109-0.644$ \\
\hline
\end{tabular}
1.

\subsection{Mach Number}

The Mach numbers obtained for microtubes with different diameters are plotted in Figure 2 as a function of $x / L$ with almost the same Reynolds number. The pressure distributions are also plotted in Figure 3. The Mach number of the smaller tube is higher than that of the larger tube and steeply increases near the outlet because the gas in the smaller tube expands near the outlet as shown in Figure 3. Also, the Mach number and pressure lines are not straight near the outlet. This phenomenon is dominant for smaller diameter microtubes as a result of compressibility. Therefore, the average Mach number between the inlet and outlet was obtained by integration from inlet to outlet. For $D=100 \mu \mathrm{m}$, both the integral and the arithmetic average Mach number between the inlet and outlet are plotted in Figure 4 as a function of Reynolds number. The inlet Mach number, the integral average Mach number and the arithmetic average Mach number is higher for the shorter length. However, the outlet Mach number is independent of micro-tube length and it can be represented as a function of Reynolds number and diameter. The values of integral average Mach numbers are lower than the arithmetic values because of the flow acceleration due to gas expansion near the outlet. Qualitatively similar results for the microtubes of $D=50$ and $150 \mu \mathrm{m}$ are also obtained. 


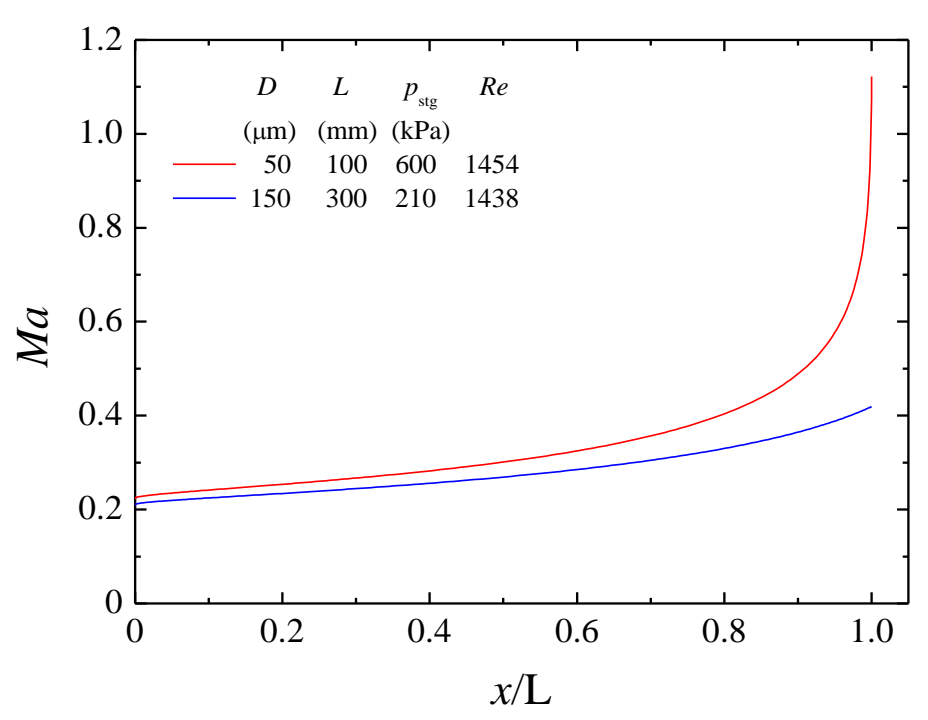

Fig. 2. Mach number as a function of $x / L$

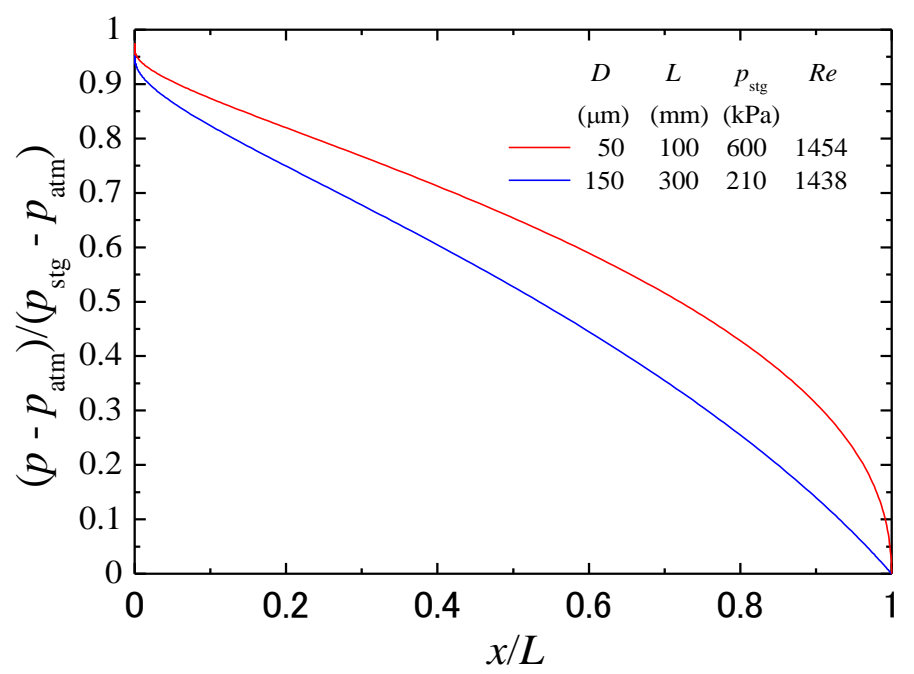

Fig. 3. Pressure distributions as a function of $x / L$

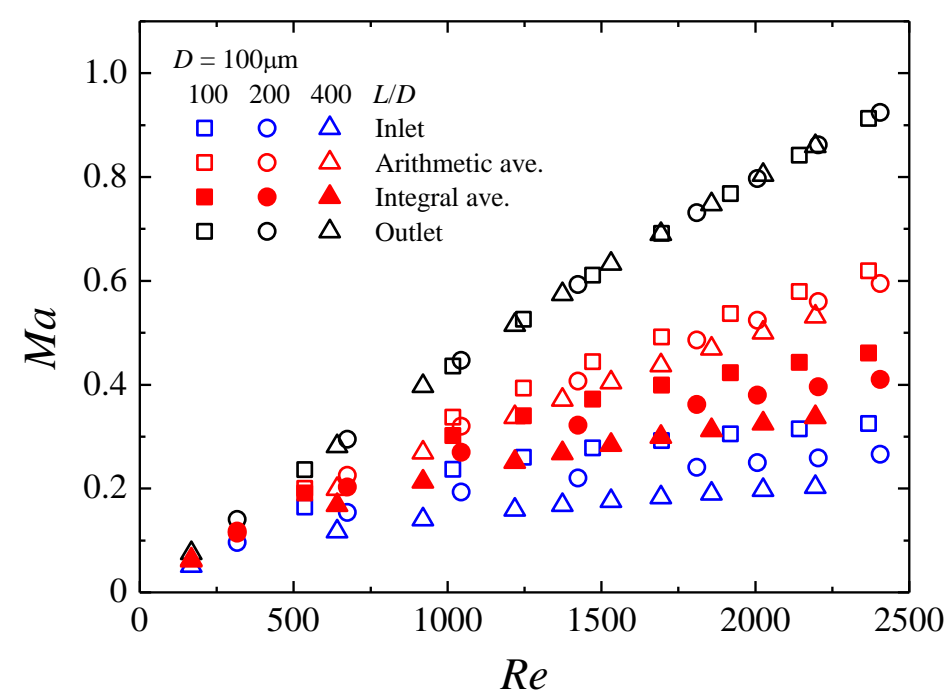

Fig. 4. Average Mach number as a function of Reynolds number 


\subsection{Average Friction Factors}

The average Darcy and Fanning friction factor between the inlet and outlet, $f_{\mathrm{d} \text {,ave }}$ and $f_{\mathrm{f} \text {,ave }}$ obtained for all tubes are plotted in Figure 5 as function of Reynolds number with white and solid symbols, respectively. The solid line and the dotted line in the figure were obtained from $f=64 / R e$ and $f=0.3164 / R e^{0.25}$ for laminar and turbulent incompressible flows, respectively.

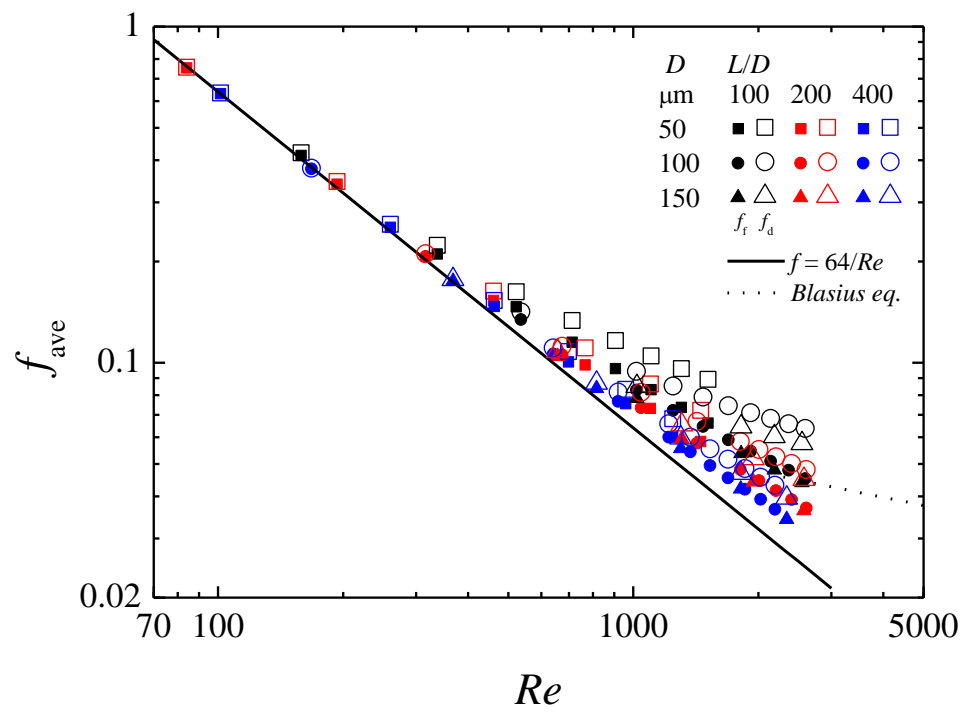

Fig. 5. Friction factors as function of $R e$

For the case of low flow velocities ( $R e \leq 300$ and $M a_{\text {out }} \leq 0.2$ as shown in Figure 4), both values of $f_{\mathrm{d} \text {,ave }}$ and $f_{\mathrm{f} \text {,ave }}$ are almost identical to the values of the incompressible theory. On the other hand, in the case of high flow velocities ( $R e>300$ and $M a_{\text {out }}>0.2$ as shown in Figure 4) both values of $f_{\mathrm{d} \text {,ave }}$ and $f_{\mathrm{f} \text {,ave }}$ deviate from the incompressible theory with an increase of $R e$ because of the entrance and compressibility effects. The difference between $f_{\mathrm{d} \text {,ave }}$ and $f_{\mathrm{f} \text {,ave }}$ is larger for $R e<300$ since flow accelerates with the increase in $M a_{\text {ave }}$ and $R e$.

The products of average Darcy \& Fanning friction factors and Reynolds number between the inlet and the outlet, $\left(f_{\mathrm{d}} \cdot R e\right)_{\text {ave }}$ and $\left(f_{\mathrm{f}} \cdot \operatorname{Re}\right)_{\text {ave, }}$, for all tubes were obtained and are plotted in Figures 6 and 7 as a function of the integral average Mach number, respectively. Local $f_{\mathrm{d}} \cdot \operatorname{Re}$ and $f_{\mathrm{f}} \cdot \operatorname{Re}$ correlations proposed by the previous study [15] were employed in order to estimate the entrance losses. In the previous study [15], the local $f_{\mathrm{d}} \cdot R e$ and $f_{\mathrm{f}} \cdot R e$ for quasi-fully developed flows as a quadratic function of Mach number, were numerically obtained and their correlations were proposed as

$f_{d} \cdot \operatorname{Re}=64-11.99 M a+263.7 M a^{2}$

$f_{f} \cdot \operatorname{Re}=64+2.703 M a+93.89 M a^{2}$

The proposed local $f_{\mathrm{d}} \cdot R e$ and $f_{\mathrm{f}} \cdot R e$ are also plotted in these figures with solid lines, respectively. Both values of $\left(f_{\mathrm{d}} \cdot R e\right)_{\text {ave }}$ and $\left(f_{\mathrm{f}} \cdot R e\right)_{\text {ave }}$ increase with an increase in the average Mach number due to compressibility. $\left(f_{\mathrm{d}} \cdot R e\right)_{\text {ave }}$ is higher than local $f_{\mathrm{d}} \cdot R e$ since $\left(f_{\mathrm{d}} \cdot R e\right)_{\text {ave }}$ includes losses due to both flow acceleration and entrance. $\left(f_{\mathrm{f}} \cdot R e\right)_{\text {ave }}$ is also higher than local $f_{f} \cdot R e$ since $\left(f_{f} \cdot R e\right)_{\text {ave }}$ includes losses due to both friction and entrance. 


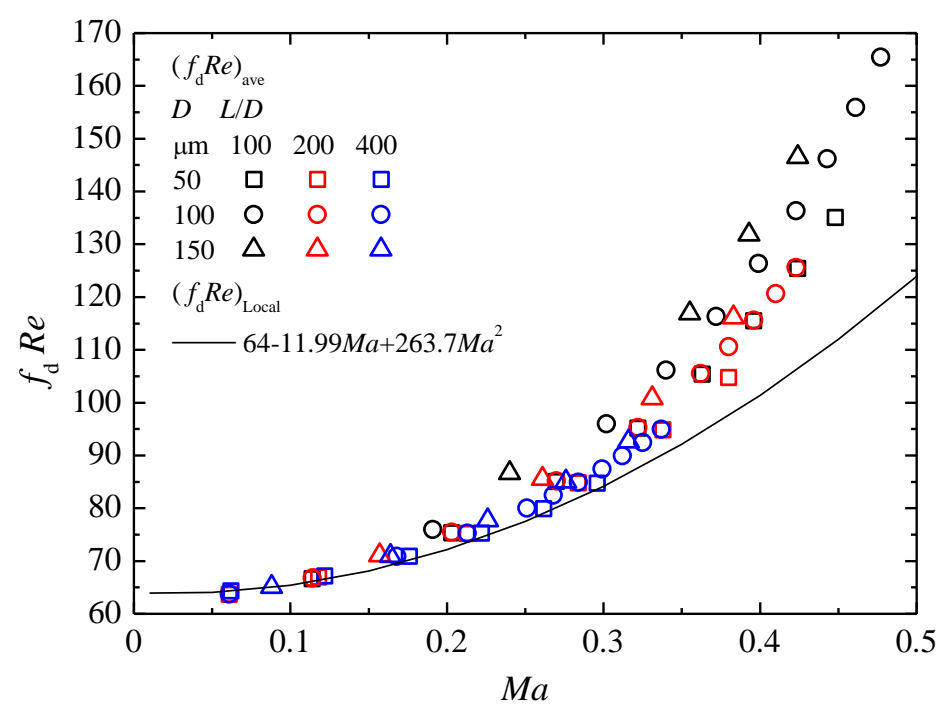

Fig. 6. $f_{\mathrm{d}} \cdot \operatorname{Re}$ as function of $M a$

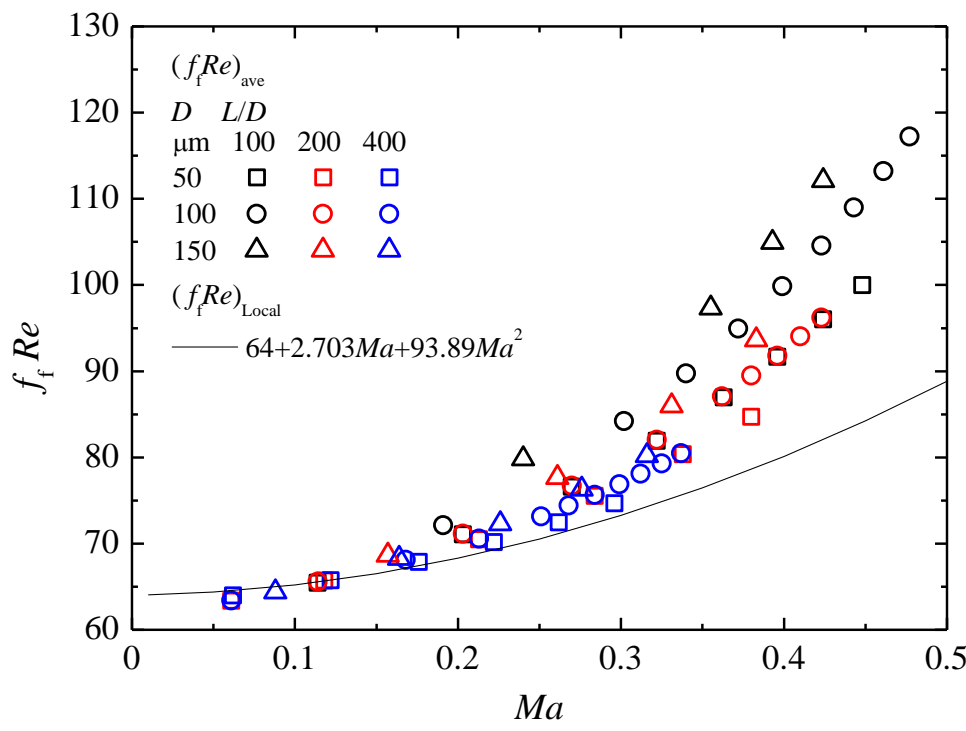

Fig. 7. $f_{\mathrm{f}} \cdot \operatorname{Re}$ as function of $M a$

\section{Conclusions}

The numerical calculations were performed to obtain $\left(f_{\mathrm{d}} \cdot \operatorname{Re}\right)_{\text {ave }} \&\left(f_{\mathrm{f}} \cdot \operatorname{Re}\right)_{\text {ave, }}$, the product of average Darcy friction factor and Reynolds number $\&$ the product of average Fanning friction factor and Reynolds between the inlet and outlet, for circular microtubes with diameters of 50, 100 and $150 \mu \mathrm{m}$ and aspect ratios (i.e. length/diameter) of 100, 200 and 400, respectively. The following conclusions were reached.

i. The values of the integral average Mach numbers are lower than those of the arithmetic values because of the flow acceleration due to gas expansion near the outlet.

ii. $\left(f_{\mathrm{d}} \cdot \operatorname{Re}\right)_{\text {ave }} \&\left(f_{\mathrm{f}} \cdot \operatorname{Re}\right)_{\text {ave }}$ are higher than local $f_{\mathrm{d}} \cdot \operatorname{Re} \& f_{\mathrm{f}} \cdot \operatorname{Re}$ since $\left(f_{\mathrm{d}} \cdot \operatorname{Re}\right)_{\text {ave }} \&\left(f_{\mathrm{f}} \cdot \operatorname{Re}\right)_{\text {ave }}$ have the entrance loss.

\section{Acknowledgement}

This work was supported by JSPS Bilateral Program (JPJSBP120199969) 


\section{References}

[1] Fung, Chang Kai, and Mohd Fadhil Majnis. "Computational Fluid Dynamic Simulation Analysis of Effect of Microchannel Geometry on Thermal and Hydraulic Performances of Micro Channel Heat Exchanger." Journal of Advanced Research in Fluid Mechanics and Thermal Sciences 62, no. 2 (2019): 198-208.

[2] Maeda, Kenshi, Chungpyo Hong, and Yutaka Asako. "Flow Characteristics of Transition Region Between Laminar and Turbulent Gas Flows Through Micro-Tubes." Journal of Advanced Research in Fluid Mechanics and Thermal Sciences 56, no. 1 (2019): 10-19.

[3] Peiyi, Wu, and W. A. Little. "Measurement of friction factors for the flow of gases in very fine channels used for microminiature Joule-Thomson refrigerators." Cryogenics 23, no. 5 (1983): 273-277. https://doi.org/10.1016/0011-2275(83)90150-9

[4] Kawashima, D., and Y. Asako. "Measurement of quasi-local friction factor of gas flow in a microtube." Proceedings of the Institution of Mechanical Engineers, Part C: Journal of Mechanical Engineering Science 230, no. 5 (2016): 782-792.

https://doi.org/10.1177/0954406215583887

[5] Yang, Chien-Yuh, Chia-Wei Chen, Ting-Yu Lin, and Satish G. Kandlikar. "Heat transfer and friction characteristics of air flow in microtubes." Experimental Thermal and Fluid Science 37 (2012): 12-18.

https://doi.org/10.1016/j.expthermflusci.2011.09.003

[6] Lorenzini, Marco, Gian Luca Morini, and Sandro Salvigni. "Laminar, transitional and turbulent friction factors for gas flows in smooth and rough microtubes." International Journal of Thermal Sciences 49, no. 2 (2010): 248-255. https://doi.org/10.1016/j.ijthermalsci.2009.07.025

[7] Turner, Stephen E., Lok C. Lam, Mohammad Faghri, and Otto J. Gregory. "Experimental investigation of gas flow in microchannels." J. Heat Transfer 126, no. 5 (2004): 753-763. https://doi.org/10.1115/1.1797036

[8] Tang, G. H., Zhuo Li, Y. L. He, and W. Q. Tao. "Experimental study of compressibility, roughness and rarefaction influences on microchannel flow." International Journal of Heat and Mass Transfer 50, no. 11-12 (2007): 22822295.

https://doi.org/10.1016/i.ijheatmasstransfer.2006.10.034

[9] Hong, Chungpyo, Toru Yamada, Yutaka Asako, and Mohammad Faghri. "Experimental investigations of laminar, transitional and turbulent Gas flow in microchannels." International journal of heat and mass transfer 55, no. 1516 (2012): 4397-4403.

https://doi.org/10.1016/j.ijheatmasstransfer.2012.04.008

[10] Kawashima, D., and Y. Asako. "Data reduction of friction factor of compressible flow in microchannels." International Journal of Heat and Mass Transfer 77 (2014): 257-261.

https://doi.org/10.1016/j.ijheatmasstransfer.2014.05.009

[11] Hong, Chungpyo, Yutaka Asako, Gian Luca Morini, and Danish Rehman. "Data reduction of average friction factor of gas flow through adiabatic micro-channels." International Journal of Heat and Mass Transfer 129 (2019): 427 431.

https://doi.org/10.1016/j.ijheatmasstransfer.2018.09.088

[12] Rehman, Danish, Gian Luca Morini, and Chungpyo Hong. "A comparison of data reduction methods for average friction factor calculation of adiabatic gas flows in microchannels." Micromachines 10, no. 2 (2019): 171.

https://doi.org/10.3390/mi10030171

[13] Hong, Chungpyo, Goku Tanaka, Yutaka Asako, and Hiroshi Katanoda. "Flow characteristics of gaseous flow through a microtube discharged into the atmosphere." International Journal of Heat and Mass Transfer 121 (2018): 187-195. https://doi.org/10.1016/j.ijheatmasstransfer.2017.12.104

[14] Asako, Yutaka, Tianqi Pi, Stephen E. Turner, and Mohammad Faghri. "Effect of compressibility on gaseous flows in micro-channels." International journal of heat and mass transfer 46, no. 16 (2003): 3041-3050.

https://doi.org/10.1016/S0017-9310(03)00074-7

[15] Asako, Yutaka, Kenji Nakayama, and Tetsuya Shinozuka. "Effect of compressibility on gaseous flows in a microtube." International journal of heat and mass transfer 48, no. 23-24 (2005): 4985-4994. https://doi.org/10.1016/j.ijheatmasstransfer.2005.05.039

[16] Hong, Chungpyo, Yutaka Asako, Mohammad Faghri, and Jae-Heon Lee. "Poiseuille number correlations for gas slip flow in micro-tubes." Numerical Heat Transfer, Part A: Applications 56, no. 10 (2009): 785-806. https://doi.org/10.1080/10407780903466436

[17] Hong, Chungpyo, Yutaka Asako, Stephen E. Turner, and Mohammad Faghri. "Friction factor correlations for gas flow in slip flow regime." J. of Fluids Eng. 129 (2007): 1268-1276. 
https://doi.org/10.1115/1.2776966

[18] Hong, Chungpyo, Yutaka Asako, and Jae-Heon Lee. "Poiseuille number correlation for high speed microflows." Journal of Physics D: Applied Physics 41, no. 10 (2008): 105111.

https://doi.org/10.1088/0022-3727/41/10/105111

[19] Hong, Chungpyo, Yutaka Asako, Koichi Suzuki, and Mohammad Faghri. "Friction factor correlations for compressible gaseous flow in a concentric micro annular tube." Numerical Heat Transfer, Part A: Applications 61, no. 3 (2012): 163-179.

https://doi.org/10.1080/10407782.2012.638513

[20] Hong, Chungpyo, Taiki Nakamura, Yutaka Asako, and Ichiro Ueno. "Semi-local friction factor of turbulent gas flow through rectangular microchannels." International Journal of Heat and Mass Transfer 98 (2016): 643-649.

https://doi.org/10.1016/j.ijheatmasstransfer.2016.02.080

[21] Hong, Chungpyo, Yutaka Asako, and Jae-Heon Lee. "Estimation of leak flow rates through narrow cracks." Journal of pressure vessel technology 131, no. 5 (2009). https://doi.org/10.1115/1.3147984

[22] Hong, Chungpyo, Yutaka Asako, Ichiro Ueno, and Koichi Suzuki. "Estimation of Flow Characteristics in Microgeometries." International Journal of Microscale and Nanoscale Thermal and Fluid Transport Phenomena 3, no. 1 (2012): 61-75. 